\title{
“¿Llegó el cartero?”*: La correofilia de José Donoso y las Anticartas de Nicanor Parra
}

"Did the postman arrive?": The mailing of José Donoso and the anti-letters of Nicanor Parra

Cecilia García-Huidobro Mac-Auliffe**

18 de febrero de 1974. Un día que puede ser como cualquier otro. José Donoso vive en Calaceite, España, un aislado poblado inserto en el duro paisaje de Aragón, donde ha habilitado un estudio en su propia casa en el tercer piso de una construcción de piedra del siglo XVIII. Ahí se encierra en las mañanas y en las tardes a trabajar en una nueva novela -que publicará en 1978 con el título de Casa de campo-, escritura que alterna con su diario, esos cuadernos que configuraron su biorritmo de tinta durante 45 años, un andamio que sustentó su fachada vital y el gran edificio de su obra; ese lugar donde se probó todas las máscaras que luego serían una suerte de santo y seña de su poética. Precisamente en su cuaderno escribe ese día:

Pero ahora, al regreso, siento que me está costando mucho meterme en la novela. Voy a hacer lo humanamente posible de NO VOLVER A CORTAR: para mí es totalmente nefasto, negativo y destructivo. Ahora he perdido más de una semana, estamos a 18 de febrero, y no hay ni señales del capítulo 9 . Tiene que salir antes de finales del mes. ¿Pero cómo? ¿Qué hacer? Estoy roto, desesperado. El capítulo ocho lo terminé el 9 de este mes: es decir, hace ocho días que no escribo. ¡Imposible!

\footnotetext{
* Este trabajo forma parte de un proyecto que cuenta con el financiamiento del Fondo Nacional de Fomento del Libro y la Lectura, Convocatoria 2020. El siguiente texto es una versión con modificaciones de la Conferencia leída en las V Jornadas Donosianas, organizadas en la Universidad Diego Portales el 8 octubre 2019.

** Magister en Literatura, Docente e investigadora Facultad de Comunicación y Letras. Universidad Diego Portales. Ciudad, país. cecilia.ghuidobro@udp.cl
} 
La depresión me mata. No se me ocurre ni una miserable idea. Y hace frío en mi estudio, porque afuera hace un hielo feroz, y viento, y la estufa no calienta. Son las 12 y media. En un rato más llegará la correspondencia, y si no he comenzado a escribir hasta ahora, difícilmente lo haré después de la llegada del cartero. En todo caso, con el mal tiempo, no saldremos a caminar esta tarde, aunque me hace falta para reanimarme, y aunque le tengo que escribir una carta bastante pesada a mi suegro, y otra a la Carmen Balcells a propósito de los “xxx", y de los dólares de la Guggenheim (...) Pero espero con ansia el correo, tras esta absurda mañana, vacía, vacía, y bastante melancólica, ya que no puedo, no logro hacer contacto con mis personajes. ¡Desesperante! Pero explicable: es igual que no puedo hacer contacto con la gente. (Cuaderno 45... 116)

"Espero con ansia el correo", será un lamento frecuente de sus diarios, lo que evidencia su adicción a las cartas. Una correofilia que probablemente adquirió por su prolongada permanencia fuera de Chile -alrededor de 16 años- a lo que hay que sumar largas temporadas en el extranjero antes y después de su autoexilio. De modo que si sus diarios son parte de su biorritmo como hemos dicho, su correspondencia - hasta ahora poco estudiada (véase Bocaz) - no lo es menos.

Volvamos a 1974 donde lo hemos dejado encerrado en una batalla consigo mismo, de acuerdo con lo que anota en su diario. Al día siguiente, retoma su preocupación por cumplir con su correspondencia a la que asigna un valor mucho más allá de la mera comunicación: "Hoy le escribí una carta a Elaine Feinstein sobre The Glass Alembic: quedé muy contento, pero siento no haber dejado copia de la carta, ya que este año cumplo 50 años y entro en la edad en que todas las cartas que uno escribe tienen significado, especialmente las cartas críticas a tan larga distancia" (Cuaderno 45, pág 141).

La primera tentación que surge ante este estado de desesperación en el que Donoso parece encontrarse y su absoluta dependencia de la llegada del cartero es asociarlo con las particulares circunstancias de ese momento. Vive en este poblado de Aragón de no más de dos mil habitantes que, además, tiene mala conectividad con urbes cercanas como Barcelona o Zaragoza. Hace cuatro meses el presidente de Chile, Salvador Allende, fue derrocado por un golpe militar. Le preocupa lo que ocurre en el país y para él, que siempre demostró una necesidad de salir 
de Chile, aunque no fuera más que para sentir y dolerse de esa sociedad que lo fue poblando de oscuros recodos que conformaron su imaginario, saber que ahora está imposibilitado de volver, lo atormenta. No es exagerado afirmar que vivió fascinado y repelido al mismo tiempo ante Chile. Como se sabe, la primera vez que se escabulló de esta sociedad que sentía asfixiante fue a los 21 años para irse a la Patagonia chilena. El año 1945 se instaló en una hacienda ovejera de ese territorio que todavía era visto como el fin del mundo - basta recordar al escritor inglés Bruce Chatwin quien incluso treinta años después haría algo similar refugiándose en esa suerte de no lugar-. A diferencia de Chatwin, que luego publicó un libro sobre esa experiencia -En la Patagonia-, Donoso no escribió al respecto, pero como narrador neto que era, luego ficcionalizó dando diversas versiones: en algunas podía ser protagonista de escenas dantescas como la tarea de degollar ovejas accidentadas a las que las aves de rapiña le comían los ojos, mientras en otras no era más que un lector de tiempo casi completo de En busca del tiempo perdido mientras el helado viento austral se colaba por todas partes. Y un escribidor de cartas, agregaría yo. Lamentablemente no se conserva la correspondencia que escribió desde la Estancia "Gringos Duros", pero es posible adivinarla a partir de las numerosas respuestas que recibió, especialmente de sus padres y que Donoso guardó religiosamente pese a la vida itinerante que llevó por décadas. Su madre desconsolada le escribe poco después de su partida:

Hijo querido:

Aquí nos tienes penando por tu ida. No me puedo acostumbrar a la idea que te has ido de la casa, y cada día que pasa me hago más conjeturas acerca de los motivos de tu viaje. Me pregunto: ite has ido por trabajar, por buscar nuevos horizontes, por aventurar, por conocer nuevos mundos o porque no estabas a gusto entre nosotros? $\mathrm{Y}$ desgraciadamente siempre caigo en lo último, lo que me tiene completamente desesperada. (Carta de su madre, 25-febrero-45)

Al principio ese cambio de horizontes que Donoso buscó infructuosamente hasta sus últimos días lo necesitaba para ampliar las minúsculas circunstancias en las que vivía cualquier "muchacho bien" santiaguino de esos años, como alguna vez dijo:

Todo era estereotipo entre nosotros, siempre demasiado semejante a mí mismo, a mi propia vida. Las experiencias se repetían hasta el 
agotamiento: me parecía que era solo esta repetición lo que ofrecían mis amigos y amigas. Al enfrentar solitario ciertas dolorosas y a veces sórdidas crisis personales, sentí en primer lugar que mi respuesta tenía que ser distinta y tal vez contraria a la de ellos. Había llegado el momento de apartarme, de buscar escondrijos acogedores para mis relaciones de mayor riesgo, y allí intercambiar sin culpas las distintas máscaras que me vi forzado a seguir asumiendo para sobrevivir como algo más que un facsímil de lo que me rodeaba. (Conjeturas de... 79-80)

Más adelante viajó para exponerse a lo diverso, y hacerlo con un marcado acento literario, tal como escribiría después en su libro Historia personal del boom.

Salir de Chile y llegar a México, tomar contacto de nuevo con Carlos Fuentes, conocer a Juan Rulfo y Lillian Hellman y William Styron y Oscar Lewis y Augusto Monterroso y a toda la nube de escritores mexicanos, me puso entero en movimiento otra vez, como cuando salí de mí país para ir a Princeton; como cuando salí rumbo a Buenos Aires; azuzó mi curiosidad sin frustrarla, alimentó mi avidez que tanto tiempo había permanecido insatisfecha. (Historia personal... 99)

No cabe duda de que para Donoso escritura y viaje obedecen a un desasosiego similar y la correspondencia fue parte fundamental de esa ecuación. Cuando alguien le consultó si vivir fuera del país había sido una necesidad para él, dijo: "En Princeton me siento tan extraño como en Chile. Esa situación de extrañeza con el mundo no depende del lugar donde se vive y tal vez sea esa sensación de extrañeza lo que nos abre las puertas al viaje" ("José Donoso: Quiero escribir..." 12).

Esa sensación de extrañeza - que terminaría por ser el signo de "lo donosiano", lo acompañó siempre. Cuando se instala de regreso en Chile el año 1981, le comenta a un amigo que para él, la única manera de vivir en este país-clínica es saliendo por tiempo más o menos prolongado todos los años.

Las cartas serán como un puente, como una promesa de una orilla donde recalar algún día. Las necesita precisamente por esa condición de desarraigo. Esa necesidad de recibir y enviar mensajes refleja su condición de náufrago existencial. "Pero el suspenso de las 
cartas que no llegan cuando debían llegar es demasiado atormentador, y no me dejan tranquilo. ¿Por qué lo espero todos los días con esta mezcla de esperanza y de angustia? ¿Como si pudiera traerme, cada día, la condenación eterna o la salvación?" (Cuaderno 45... 135).

Desde esta perspectiva, las cartas se revelan como parte significativa de su biografía y de su obra. La correspondencia entonces, es el lugar donde tomar distancia para acercarse a los demás, se torna un hábito permanente en él. Mientras aguarda al cartero en Calaceite allá por 1974, rememora antiguas esperas:

En México, recuerdo, Carlos Fuentes y yo salíamos a la esquina de Galeana para esperar al cartero, y enloquecía esperando a cada rato, a cierta hora, escuchar el silbido con que se anunciaba en las calles próximas. En Iowa, cuando vivíamos en Rural Route, recuerdo que tenía mi estudio en una especie de mirador, por donde continuamente, en la mañana, mientras escribía, atisbaba para ver si se acercaba el coche destartalado, del correo rural. Y en Princeton, después de una semana con Fernando Balmaceda en Washington, o con Nemesio Antúnez e Inés en Nueva York, la maravilla, el deslumbramiento de encontrar MILES de cartas debajo de la puerta de mi habitación en Edwards Hall. Creo que desde Princeton tengo la angustia, la esperanza y el goce del correo: las cartas de casa, las de Techy Edwards, las de Manané Silva, las de Margarita Aguirre, todas. Están en Iowa esas cartas ahora. Me gustaría mucho tenerlas. La desesperación cuando Inés y Nemesio se fueron a París y jamás me escribieron: la desolación. Luego, una carta. Ilustrada. La hice enmarcar. ¿Dónde estará ahora esa absurda y esperada carta de Nemesio - fue él, no Inés quien escribió- que sintetizaba toda mi frustración y mi amor por ellos? (Cuaderno 45... 135)

Se aprecia que Donoso se refugió en el género epistolar para relacionarse con los otros. Un espacio desde donde situarse y protegerse de sus inseguridades. Si el narrador escogió la escritura creativa para explorar el mundo -interior y exterior- se valió permanentemente de la escritura epistolar para interactuar con los demás, aunque en realidad Donoso nunca respetó la frontera entre sus diversas escrituras. Muchas veces se valió de la escritura para socializar y la carta fue el mejor vehículo para hacerlo. Algo que no cambió ni cuando regresó a 
vivir a Santiago, ni cuando se hizo mayor, ni cuando la tecnología ofreció alternativas más rápidas como el fax. Esa curiosidad, esa pulsión por los mensajes que llegan, que invaden su territorio como nuevos horizontes, lo acompañó hasta el final. Nunca dejó de estar alerta, preguntándose “¿llegó el cartero?”.

Un día que puede ser como cualquier otro, esta vez en su casa de la calle Galvarino Gallardo, en Santiago. Todo parece estar organizado en torno a la llegada del cartero tal como ocurría veinte años antes en Calaceite. Lo relata su hija Pilar en Correr el tupido velo (2013):

Las comidas también eran un acontecimiento, sobre todo a la hora de almuerzo. Mis padres se sentaban a la mesa, con invitados o no, y pedían el teléfono que se traía con un alargador desde la cocina y se dejaba sobre el comedor. Pero lo más importante era la espera del cartero, que solía aparecer en ese momento. Las cartas y paquetes también se colocaban sobre la mesa, en el ritual de abrir las esperadas noticias, en especial las de la agente literaria Carmen Balcells, por alguna nueva edición de un libro, o alguna invitación. Mientras, se hablaba por teléfono y en eso transcurría el almuerzo, entre bocado y bocado (Correr el ... 295)

¡Una verdadera performance! Una escena que conmueve y divierte a la vez.

"Soy yo mismo la materia de mi libro" es una de las más certeras afirmaciones del notable ensayista Montaigne. La tomamos para aplicarla a Donoso, pero quizás habría que hacer un leve desplazamiento para decir que él mismo es la materia de todos sus escritos, no solo de sus libros. Fueran ficción, crónicas, diario íntimo o correspondencia. Todos forman parte de este tinglado - andamio lo llamamos al comienzoque sustentó su fachada vital y su obra. Seguirlo a través de sus cartas abre nuevas aproximaciones que suman ficción a la ficción que él hizo de sí mismo. Como bien dijo Claudio Guillén (1991) refiriéndose al género epistolar, "el yo que escribe no solo actúa sobre el amigo, sino sobre sí mismo, viéndose desdoblado y objetivado sobre el papel” (35-39).

Me propongo aquí sentarme - como se hacía en la casa de Donoso- en la mesa bien servida luego de la llegada del cartero. El menú epistolario en esta oportunidad será el intercambio de Pepe Donoso con Nicanor Parra. 


\section{Las cuentas claras}

Todos quienes hayan leído los diarios íntimos de José Donoso - algunos ya publicados otros aún inéditos- se sorprenderían al revisar su correspondencia. Es como si esa enorme cantidad y variedad de cartas fuera un mundo paralelo al relatado en sus cuadernos. En muchas de ellas se ventilan situaciones relevantes, a veces críticas, las que permanecen ausentes en los diarios íntimos. ¿Son dos voces distintas las que escriben, se trate de diarios o cartas? ¿Prefiguran distintos yoes?

Digo esto porque revisando las cinco cartas que Nicanor Parra envió a Donoso existentes en los archivos de Iowa y Princeton, pude constatar que pese al encontronazo que vivieron como veremos más adelante, en los diarios no aparece ninguna alusión al conflicto que lo tiene desesperado como le confidencia a su amigo Hans Ehrmann, periodista cultural y editor de Ercilla: "Una notita rápida, aterrada e iracunda, acompañándote fotocopias de la carta de Nicanor. ¿Qué hace uno en un caso así?" (2 junio 1970)

Desconozco con exactitud cuándo conoció a Parra, pero Pepe lo entrevistó a los pocos meses de convertirse en reportero de la Revista Ercilla en 1960. Se juntaron en su casa en La Reina "desde donde domina Santiago" ("Parra reniega..." 28) . El poeta habla de su infancia, de su padre tarambana, de su vocación de ser carabinero, su hermano payaso, de su esposa sueca, de sexo, del Premio Nacional (que recibiría nueve años más tarde).

Nicanor había publicado seis años antes sus Poemas y antipoemas, libro con el que dio, como sabemos, un golpe a la cátedra. En 1958 apareció La cueca larga ilustrado por el pintor Nemesio Antúnez, quien el año anterior había realizado la portada de la primera edición de Coronación. Extrañamente Donoso no menciona La cueca larga y por el contrario afirma que desde 1954, Parra no ha publicado nada. Como sea, el poeta cuenta que tiene listo un nuevo libro. Duda como titularlo. Baraja nombres como "Baile sobre una tumba", "Licencia poética", "Pan pan, vino vino,, “Las cuatro operaciones", “Versos de salón”, que terminaría por imponerse. "Buscar un título es como escribir el más largo y más difícil de mis poemas" ("Parra reniega..." 28), afirma Parra en la entrevista.

En la misma página que comparte con un aviso que publicita " $\mathrm{Eu}$ ropa a solo 24 horas en vuelo directo por Boac Comet Jet" y que grafica 
la complejidad de los viajes en esos años, Parra concluye: "Mi unidad es el verso, que en mi poesía aparece como aislado, como una serie de pedradas lanzadas hacia el lector" ("Parra reniega..." 29.

El carteo comienza un par de años después, y al principio no hay pedradas. La primera es una breve nota y llama la atención que no hubiera recurrido al teléfono para un mensaje como este. Fechada el 28 de marzo de 1963:

Dear Pepe,

Magnífico

Gracias

Hay que celebrar! Ustedes tienen citroneta. Los espero en La Reina el sábado por la tarde. Concurrirán los chinitos de Pekín. (Carta a José... )

Efectivamente, los Donoso se desplazan en citroneta. En realidad María Pilar Serrano, su mujer, lo hace. Pepe contó más de una vez que le pidió tres requisitos para casarse con ella: Haber leído En busca del tiempo perdido de Proust, haberse sicoanalizado y saber manejar, porque él jamás lo haría.

Su deseo de salir de Chile del que ya hablamos comienza a materializarse. Por eso las siguientes cartas, Parra se las envía al extranjero. La primera a México, cuando los Donoso arriendan un pequeño estudio en la parte trasera de la casa de Carlos Fuentes, algo así como el epicentro de la movida, como contaría después en Historia personal del boom.

Toda la picaresca literario-plástica-cinematográfica-teatral-social de México, además de la internacional, desfilaba por la casa de Carlos Fuentes y Rita Macedo. Pasaban editores de los Estados Unidos, agentes literarios, directores de películas, de revistas, de empresas. De Cuba llegaban, además de invitaciones, dignatarios como Roberto Fernández Retamar, que deslumbró al ambiente mexicano con el refinamiento de su cultura. (Historia personal... 106)

Al comenzar el año 1965 Nicanor Parra le escribe entre otras cosas para trasmitirle una invitación de la Casa de las Américas de Cuba, en esos años el punto de encuentro del mundo cultural latinoamericano. Eran todavía los buenos tiempos de Parra con Cuba que luego de la 
taza de té con la señora Nixon en la Casa Blanca en abril de 1970 cambiaría radicalmente.

Querido Pepe, procedo a transcribirte una carta de Haydée Sta. María (Casa de las Américas) fechada en La Habana, el 9 de noviembre de 1964 y dirigida a Isidora Aguirre. Llegó ayer a mis manos, vía Margarita Aguirre, que está en Chile de nuevo. (muerte de su señor padre).

Una vez más recabamos su cooperación. En Chile hemos invitado, para integrar el Jurado que otorgará el Premio Literario Casa de las Américas 1965, a los siguientes escritores:

Fernando Alegría

José Donoso

Nicanor Parra

Ricardo Latcham

Manuel Rojas.

Estas invitaciones las cursamos en el mes de julio y hasta la fecha solamente hemos recibido contestación de Fernando Alegría, a quien le es imposible asistir. Del resto de los escritores estamos pendientes y quisiéramos tener las contestaciones a más tarde el 15 de diciembre, a fin de poder confeccionar los jurados de los cinco géneros en con la debida anticipación. Como sabemos las demoras del correo, quisiéramos que de acuerdo con sus posibilidades, contactara a dichos invitados con el objeto de conocer sus respuestas o, en el caso de que no hayan recibido nuestras cartas, y les hablara de nuestra invitación.

De usted, sabemos que tendremos noticias sobre este asunto, una vez más reciba el testimonio de nuestro reconocimiento y amistad. Firmado. Haydée Sta. María, Directora.

Ahora la que sigue es la voz de Parra:

Extraña carta (en lo que a mí respecta al menos) puesto que yo contesté afirmativamente en el mismo mes de julio. En agosto volví a escribir, en vistas de que no recibía confirmación, esta vez obtuve respuesta (no de la señora Haydée sino de un señor cuyo nombre no recuerdo en este momento). ¿Y tú? Que yo sepa jamás recibiste la carta invitación. 
Con Ricardo Latcham, otro de los invitados fantasmas, hablé por teléfono anteayer. Dice que ha estado cablegrafiando tupido y parejo a La Habana, pero sin ningún resultado. De Rojas y de Fernando nunca oí decir siquiera que hubiera(n) sido invitado. Something must be the matter. Quería comunicarte todo esto, para que tú, que te encuentras en una situación privilegiada respecto de nosotros, des los pasos que consideres pertinentes. Después de todo ahí hay una Embajada Cubana y las comunicaciones entre Santiago de Chile y La Habana parecen estar interrumpidas irremediablemente.

That's about all. Sería formidable que pudiéramos pasar juntos el mes de La Habana. (imagino que María Pilar quedaría automáticamente incorporada al grupo, en caso de que tú pudieras aceptar la invitación). De acuerdo con la carta invitación habría que estar en La Habana el 15 de enero. Sería pingüe quedarnos allá hasta fines de febrero.

Feliz año nuevo, abrazos para María Pilar.

Saludos para Carlos y Rita (Carta a José Donoso, 1965)

Donoso finalmente no fue a La Habana. Y no deja de sorprender que en 1964 fuera considerado como jurado para el prestigioso Premio Casa de Américas, pues siempre tuvo cierta distancia con el régimen castrista, algo que marcaría también las diferencias con sus congéneres del boom.

Desde México los Donoso se trasladan a Iowa, donde Pepe se incorpora al Programa de Creative Writing de esa universidad. Parra también pasa temporadas en Estados Unidos y se escriben intentando verse. El 17 de marzo de 1966 desde Louisiana State University, en Baton Rouge, le comenta a un Donoso convertido en queridísimo:

Dearest Pepe,

Aquí me tienes de vuelta al punto de partida, después de veinte y tantos años. Experiencias para un novelista.

Noticias traigo pocas pero importantes. Algunas terribles: Enrique (Lihn) obtuvo este año el premio para poesía de la Casa de las Américas. Como ves estamos corriendo en buen caballo. A Juan 
Agustín (Palazuelos) ${ }^{1}$ lo he visto una vez en los últimos meses, publicó su segunda novela. Masacre de mineros en Chile, etc., etc.

Experimenté una gran alegría cuando llegué a B. R., Miller Williams me dijo que vendrán ustedes durante el semestre. ¿Cómo está ese viaje?

En la práctica mi situación es la de Poeta Residente.

Obligaciones académicas casi nulas. Renta semestral contratado primer semestre $\$ 5.500$, más viaje de ida y vuelta y más mi complemento para afrontar el alza del costo de la vida ¿pasable?

Grandes abrazos.

Todo mi corazón para María Pilar. (Carta a José Donoso, 1966)

En abril de ese mismo año, también desde Estados Unidos pero sin especificar desde qué ciudad escribe, Parra reclama porque no podrán encontrarse y de paso no escatima alabanzas:

Dear Pepe,

Miller me dice que no pasarás por aquí de ida a México. Lástima: nos estábamos preparando. Yo dispongo de un departamento donde pudieran haberse arranchado. Tengo dos dormitorios. Lo dejo a fines del mes mayo. Todavía sería tiempo...

Entiendo tus razones. No las comparto, pero simpatizo con ellas. Chile es un país bastante jodido. Mi solución es La Reina. Claro que la pobreza a mí no me asusta porque siempre he sido pobre. Al contrario solo me siento yo mismo en una población callampa. Ahí renazco y me transformo en un torito. A lo mejor a ti te ocurrirá lo mismo. Try!

Cortázar y Vargas Llosa tampoco viven en S.A. (Sudamérica). Pero Rulfo sí. I don't know. Tú sabes lo que haces. Lástima eso sí de que

1 Juan Agustín Palazuelos (1936-1969) novelista de la generación de los Novísimos (junto a Skarmeta, Wacquez). En 1962 publica su primera novela, Según el orden del tiempo, causando un gran impacto al considerarla una suerte de proyecto por construir la antinovela acorde a lo que Parra estaba haciendo con la poesía. Su esperada segunda novela, Muy temprano para Santiago, de 1965 a la que Nicanor Parra hace aquí referencia, sin embargo fue una decepción para la crítica que la calificó como más realista y menos irónica. 
nos prives de tu persona a los chilenos que te queremos y admiramos. Deprimente, lo mismo que hizo la Gabriela.

Yo comienzo a pensar en las maletas. Renuncié a Cornell (me habían invitado a dar una charla) y a lo mejor renuncio también a California donde también hay un par de recitales. Estoy que corto las huinchas por volver a La Reina.

Claro que me encantaría concurrir a ese taller literario, después de pasarme un tiempecito en Chile. Parto de la base que tú diste mi nombre: Gracias una vez más, ¿cuándo voy a poder devolverte la mano? Los rusos no contestan jamás las cartas. $Y$ a ti no te interesa Cuba. En tu caso no conviene. Claro está. Tu porvenir está aquí.

¿Te ha pedido Emir Rodríguez Monegal algo para su MUNDO NUE$\mathrm{VO}$ ? Porque no le envías un cuento (...)

En este momento acabo de recibir una invitación para visitar al padre Thomas Merton en Kentucky. Él es uno de mis traductores. Lo visitaremos juntos con James Laughlin en los primeros días de mayo.

Abrazos para ti y besos para María Pilar. (Carta a José Donoso, 1966)

Hasta aquí las cartas reflejan la historia de una amistad que se mantiene y podríamos decir que se acrecienta.

\section{¿Quién tiene la razón?}

Todo cambia en 1970 cuando Nicanor está en California y Donoso se ha radicado en España. La revista Triquartely (1969) le había encargado un par de años antes una antología de literatura latinoamericana actual que sufre toda clase de contratiempos, pero que finalmente se publica a fines de $1969^{2}$. Con la colaboración de William Henkin, Donoso selecciona más de setenta autores entre escritores reconocidos y emergentes. No obstante, signo de los tiempos, la antología incorpora solo cinco son mujeres: Clarice Lispector, Elena Garro, Isabel Freire, Basilia Papastamatiu, y Nélida Piñón. Los autores chilenos incluidos son Neruda, Efraín Barquero, Alberto Rubio, Gonzalo Rojas, Gonzalo

2 Sobre los problemas y conflictos que retrasaron la aparición de este número en el que "an Obscure Northwestern University Magazine (Barely) Introduced the U.S. to Modern Latin American Literature" al decir de Arndorfer, véase "Lost in translation" de Jim Arndorfer https://bookandfilmglobe.com/fiction/lost-in-translation-triquarterly/ 
Millán, Enrique Lihn, Miguel Arteche y Oscar Hahn. Donoso se autoantologa con su cuento "Paseo". Y naturalmente publican a Nicanor Parra, con tres poemas:

To the chicken guts que corresponde a un fragmento del antipoema "La cueca larga"; A man y Unpublished artifacts, que incluye ocho artefactos, reproduciendo solo la parte textual, sin ilustración. Entre otros: "USA. Where liberty is a statue" y "SYMPOSIUM Cuba, yes/Yankees, also".

Fue cuestión de tiempo para que se desencadenara el encontronazo. $\mathrm{O}$ al menos una carta furiosa que Parra le escribe al ver la publicación. A tanto llega su indignación, que como toda despedida anota "ni siquiera vale la pena que firme."

Dear Pepe:

Las cuentas claras:

Accidentalmente me cruzo en tu Triquarterly (2 ediciones) y

$1^{\circ}$ ) yo no he autorizado la publicación de esas guifas: no me representan en lo más mínimo (fuera de UN HOMBRE) que crestas es eso de TO THE CHIKEN GUTS -cómo se les ocurre traducir un poema folklórico (una fracción además)—. Qué chuchas es eso de UNPUBLISHER ARTEFACTS. Ese título no es mío. Por qué se meten a enmendarme la plana. ARTEFACTS y se acabó; pero tampoco porque los Artefactos son un conjunto I-N-D-I-V-I-S-I-B-L-E OK? Suman 300. O todos o nada.

$2^{\circ}$ ) cómo es posible que hayan pasado por encima de poemas como LA VÍBORA

\section{LA TRAMPA}

LOS VICIOS...

SOLILOQUIO

\section{DISCURSO FUNEBRE}

como agua por espalda de pato. No sé de qué culparles; de negligencia guevona o simplemente de mala fe parida.

$3^{\circ}$ ) donde están los honorarios???*

Ni siquiera vale la pena que firme.

Los Angeles (Ca) - mayo 1970

*Este texto irá en mi próximo libro. (Carta a José Donoso, 1970) 
No es difícil coincidir con la reacción de Parra cuando se traduce una expresión popular como es a la tripa-pollo como "to the chicken guts", transgrediendo completamente su significado y rompiendo su musicalidad. Un verdadero desencuentro literario que podría titularse "lost in traslation", ya que todo el antipoema es traducido con esa misma perspectiva:

On the top of a hill

Of one thousand slopes

Two ballerinas chattered

Tooth to tooth.

Tooth to tooth, yes,

Potatoes with seaweed,

Two little birds hugged

Craw to craw.

Craw to craw, yes,

Embrace and kiss,

Two skeletons struck

Bone to bone.

Bone to bone, come on,

Pancho is a nickname for Francisco,

Don't get the idea

That I'm from the National Treasury.

That I'm from the National Treasury, yes,

The nightingales

Will never tire

Of sucking flowers.

A sneeze is not a laugh,

Laughter is not weeping;

The parsley is good/but not good enough.

Come on, laughter with weeping,

The song is over. ${ }^{3}$

3 En la punta de un cerro/De mil pendientes/Dos bailarines daban/Diente con diente./Diente con diente, sí/Papas con luche/Dos pajarillos daban/Buche con buche./ Buche con buche, sí/Abrazo y beso/Dos esqueletos daban/Hueso con hueso. / Hueso con hueso, ya pus/Pancho Francisco/No te estís figurando/Que soy del fisco/Que soy del fisco, sí/Los ruiseñores/No se cansarán nunca/De chupar flores./ Estornudo no es risa/Risa no es llanto/El perejil es bueno/Pero no tanto./ Anda, risa con llanto/Se acabó el canto. 
Es verdad que traducir la creación parriana ha sido siempre un desafío especial porque la antipoesía está anclada en el uso del habla en su estado más fresco, indómito y coloquial. Pero sin duda la forma de abordarlo en esta oportunidad, es indefendible y constituye un error garrafal. Por algo Parra le recrimina especialmente la peregrina iniciativa de "traducir un poema folklórico".

Como era de suponer, la carta, pero sobre todo su frase última - "este texto irá en mi próximo libro"-, hizo entrar en pánico a Donoso. Se desahoga escribiéndole a Hans Erhrman:

Vallvidrera, 2 de junio, 1970

Querido Hans:

Una notita rápida, aterrada e iracunda, acompañándote fotocopias de la carta de Nicanor. ¿Qué hace uno en un caso así? Tengo carta tuya (sic) diciendo que se autorizaba la publicación. Pero esto no tiene importancia. ¿Qué le pasa a Nicanor? ¿Es la arterioesclerosis que comienza a hacer estragos en la generación del 38 - ya hemos visto al pobre Fernando Alegría-. Está loco... and tea with Mrs. Nixon on top of it all. Yo no sé qué hacer. Cada vez que me meto con chilenos las manos me quedan sucias con mierda de alguna manera, ya vez lo de Palazuelos ${ }^{4}$ en Iowa que cerró para siempre las puertas de esa universidad para escritores chilenos... y probablemente para mí, if I wanted to go there, in a pinch. ¿Qué hago con lo de Nicanor, Hans? ¿No contestarle? Solo un escritor más tuvo la reacción de Parra, y con mucha más razón... no te quiero decir quién, pero ese también está más loco que una cabra y además es argentino: for (sic) fin quedamos íntimos.

Escribirle una carta a Nicanor (esta, enviada desde California, se me ocurre que puede haber sido instigada por $\mathrm{F}$ (ernando) Alegría), explicándole que en las últimas etapas de la revista estuve agonizando en un Hospital de Fort Collins y no pude revisar el material, sería inútil. But the guy is obviously out of his mind, de modo que no saco nada. ¿Qué hago? Tú no hagas ninguna gestión, ningún co-

4 Donoso recomienda a Palazuelos en la Universidad de Iowa, pero a último momento este desistió, lo que dejó muy molesto a Pepe. 
mentario, sin consultarme a mí antes. Escríbeme rápido, que me urge una respuesta.

Un abrazo.

Pepe. (Carta a Hans Erhman, 1970)

En una esquina del papel agrega: "Ya me habían llegado rumores que con los años a Nicanor se le estaba produciendo una pequeña confusión entre sí mismo y Dios, Zeus Tonante o qué se yo que pero nunca creí que fuera otra cosa que maledicencia ni que llegara a este punto de ridículo".

Ehrmann conociendo la neurosis de su amigo, se aplica para poner paños fríos al conflicto. Trata de dar un contexto a la reacción aireada de Nicanor e incluso matiza respecto de la importancia de pedir autorización a la hora de hacer una antología:

Querido Pepe,

Parece que en algunas cosas la experiencia de la vida me ha dado una mayor paciencia y fortaleza: ya es muy poco lo que suelo inmutarme por exabruptos como los de Nicanor. Tampoco es él el único que cae en ese tipo de cosa. Pero me imagino su carta y que, al caerte de improviso, te haya afectado.

En Los Ángeles, estuvo en casa de un profesor chileno que se llama Leonidas Morales. Es probable que la antología la haya visto allí. En los tres días más o menos que pasó allí, también recibió la noticia de que los cubanos lo habían desembarcado del jurado por su tecito con madame Nixon. Eso lo aterró mucho y puede ser en parte responsable por el tono de la carta en sí.

Ahora bien, Parra no deja de tener cierta razón: no por lo que alega de lo representativo o no de su obra (el antologador es el juez de eso, me imagino), ni por las traducciones. Sino por la autorización. Desde que publicó su antología en "New Directions", la que se vendió muy bien en Estados Unidos, recibe consecuentemente pedidos de poemas y también se los pagan muy bien. El hombre se administra en ese sentido: Demasiado, para mi gusto, pero allá él. En ese sentido lo de la antología no significaba para él un "darlo a conocer" allá como sería el caso de otros. Por eso, al margen del aspecto legal, es justo que alegue que nadie le pidió permiso para 
publicar los poemas. Pero tampoco le hace daño el asunto y no es para insultar a nadie ni armar escándalos.

Antes de responder tu pregunta ¿Qué hacer? Algunos antecedentes más. Al viejo regalón de la izquierda chilena lo han estado atacando duro y parejo en la prensa de siniestra de aquí desde su regreso. Está muy afectado, exasperado, enloquecido, por todo esto. Del recorte que te mande desprenderás sus razonamientos. Muy débiles, por cierto, en su aspecto político. Envió un cable a Roberto Fernández Retamal a Cuba pidiendo reconsideración del desconvite. La respuesta al cable llegó en otro: "Ya que usted apela justicia revolucionaria, como revolucionarios condenamos su confianza en el imperialismo. Imposible admitir fecha (sic) su visita Casa Blanca como período esperanzas paz negociaciones cuando situación indochina muestra hace años criminal actitud imperialismo norteamericano. Reciente agresión Camboya solo agrava esta situación así como masacre estudiantes Kent añade nuevos nombres a la larga lista mártires negros y blancos Estados Unidos. No tenemos honor ser tribunal revolucionario, pero confirmamos retiro invitación".

No lo he visto desde que este cable se publicó, pero por una entrevista que se le publicó hoy está transformándose en un energúmeno reaccionario. Creo, en todo caso, que debes escribirle, pero solo en un tiempo más cuando el hombre esté más tranquilo y haya cierta esperanza de que no te envíe otra carta como la anterior. Si quieres, te aviso.

En cuanto a tu desencanto con Chile, creo que el país es más que el mundillo de sus escritores y artistas. No es la única parte donde son una tropa de envidiosos. Y no le hagas caso a Nicanor. No dejes que te deprima ni te eche a perder el ánimo. Mejor juega a la pelota con Pilarcita. (Carta a José Donoso, 1970)

\section{De natalicios y celebraciones}

A partir de este episodio, desaparecen las huellas de la relación epistolar entre Nicanor Parra y José Donoso, al menos en los mencionados archivos. Pero como es de suponer, eso no significa que no se hayan encontrado. Algunas pistas es posible seguir en su diario íntimo. Como por ejemplo cuando en 1984 Donoso escribe: "Luego, Enrique Lafou- 
rcade nos convidó a María Pilar, a mí, a Nicanor Parra y a Virginia Cox a su nuevo, lujosísimo (para Chile) departamento en la calle Alcántara: para "apantallarnos", supongo, ya que no creo que de Enrique salga absolutamente nada que se pueda parecer al afecto, y definitivamente, cualquiera acción suya, es una forma de sobrecompensación" (Cuaderno $56 \mathrm{p}$ 139).

Más adelante agrega:

Nicanor, muy cariñoso, contando lo de la Revista Araucaria, el computo de poetas y prosistas de Chile, en el que yo salgo primero, y él, después de Neruda, Mistral y Huidobro, muy generoso de parte de Parra, que no es notablemente generoso ni jamás lo ha sido, no se ha sabido que lo es (pertenece, o pertenecía a la escuela LihnLafourcade, más bien, con sus payasadas bien intencionadas pero pasadas de moda y que ya no interesan). (Cuaderno $56 \mathrm{p} \mathrm{140)}$

Como se ve, un caprichoso azar parece ocuparse de hacerlos coincidir. El año 1994, por ejemplo, un Chile entusiasmado con el retorno a la democracia y viviendo una suerte de primavera cultural, se vuelca a celebrar a sus artistas. Y excusas no faltaron: estaban los cien años del nacimiento de Pablo de Rokha, los noventa de Neruda. Por supuesto que para ellos hubo velas cumpleañeras y una exposición bibliográfica organizada por la Dirección General de Archivos y Museos, Dibam. Pero las fiestas en grande fueron para los vivos: los 80 años de Parra y los 70 de Donoso. Las de Nicanor - corresponde-, más bien callejeras, lúdicas. Organizadas por Fernán Meza desde la Facultad de Arquitectura de la Universidad de Chile, entre otras actividades se inauguró la plaza portátil a un costado del Supermercado Unimarc, ubicado en la avenida Portugal muy cerca de la Alameda. El Mercurio explica: El concepto de "plaza portátil", responde a una especie de juego, gracias al cual la ceremonia se transforma en algo parecido a una fiesta ritual y desde la cual la "Plaza Nicanor Parra" podrá ser trasladada de un lugar a otro, a través del tiempo y el espacio físico. Según el profesor Meza, el objetivo principal de esta fiesta a la que ha sido invitada toda la comunidad es incentivar y promover la participación de los estudiantes en este tipo de actividades, que despiertan el interés por la cultura y el arte en general.

En el homenaje participarán: La Orquesta Juvenil de la Facultad de Artes de la Universidad de Chile, el Quinteto Cámara Brass del Conser- 
vatorio Nacional de Música, la Compañía de Danza Moderna La Vitrina y los Bufones de Parranda.

Asimismo, al acto adhirieron la Dibam; la Municipalidad de Santiago; el Comité de Adelanto de la Remodelación San Borja; Machitún 94; el Comando Autónomo Parra al Nobel, y los grupos de teatro El Espejo, La Memoria, Ictus, Imagen y La Mancha (El Mercurio 6).

No pudo escapar del todo de la formalidad, pues ocho días después ese mismo diario informó que la apertura de las actividades de celebración contó con la participación del Ministro Secretario General de Gobierno, Víctor Manuel Rebolledo. En su discurso, subraya el periódico, el ministro afirmó que "Nicanor Parra nos ayuda a sentirnos en casa en nuestro propio país, en nuestras propias vidas" (El Mercurio C18). ¿Un ministro más parreano que el mismísimo Nicanor?

Rafael Gumucio en su destacada biografía de Parra registra una instantánea de ese momento donde el poeta y el narrador parecen hablar desde su diferencia e incluye una elocuente fotografía para demostrarlo:

Parra y Donoso. Los veo en un recorte del diario La Época, en septiembre de 1994: están en un homenaje de la Municipalidad de Santiago, sentados lado a lado. Donoso, su barba y sus anteojos que esconden su incomodidad entre inglesa y talquina. Parra, curtido por los años, más seguro que nunca de sus gestos. Dos posibilidades, dos maestros, el novelista del encierro, la vigilancia social, las casas de campo, los prostíbulos infernales, que llevó el realismo chileno hasta el delirio y los monstruos recónditos en patios interiores. Todo eso que Parra, el macho alfa sentado al lado del bisexual secreto que era Donoso, negaba a golpe de chistes de cantina y ecuaciones. Donoso rozaba la poesía sin salirse nunca del corset de la novela, Parra escribía cuentos en verso sobre borrachos y muertos felices. Eso es lo que hacía reír a mi abuela: Donoso era un niño envejecido, Parra un viejo aniñado. (Gumucio 428)

Las festividades del niño envejecido - Donoso-, en cambio, estuvieron rodeadas de solemnidad. El presidente Eduardo Frei lo condecora con la orden al mérito Gabriela Mistral, le pone una banda que lo hace parecer un dictador de Marulanda y las fotos lo muestran encantado. Luego un Coloquio organizado por el Ministerio de Educación y el Departamento de Literatura de la Universidad de Chile con un nu- 
trido programa con cerca de cincuenta escritores y una delegación con grandes invitados como Sergio Pitol y José Saramago que unos años después recibiría el premio Nobel. En paralelo se lleva a cabo una exposición titulada "Imágenes donosianas" con obras de Patricia Israel, Ismael Frigerio, Gracia Barrios, entre otros (División de Cultura 1997).

Pese a que en el Coloquio se realizó una mesa sobre la generación del 50 en la que intervinieron Alfonso Calderón, Guillermo Blanco, no todos sus miembros celebraron el cumpleaños donosiano. Enrique Lafourcade en su influyente columna dominical, el 4 de septiembre de 1994 o sea un día antes del cumpleaños del poeta, ironiza:

¿Quiénes organizan estos homenajes?

Muchas veces es la mujer o la familia. En otras, los propios interesados, para reanimarse. Aunque hoy hay aportes substanciosos de las instituciones culturales del Gobierno. Solo que los 70 años no me dan garantías estéticas totales respecto de un escritor determinado. ¿Están escribiendo mejor que a los 50, o a los 60?

En cambio, a los 80 todo tiene otro gusto. Uno escribe "agú" y el lector saborea la ambrosía de una lengua redescubierta. ¿Cómo? ¿Tan veterano y haciendo estas gracias? (Lafourcade D32)

Un mes más tarde, Lafourcade vuelve a la carga:

En estos días fue mi cumpleaños. Me escapé escondidamente a Buenos Aires por temor de que el Presidente Frei me fuera a dar una medalla. ... De manera que estuve ausente y perdí algunas páginas de la historia de Chile, como los cumpleaños de Nicanor Parra y José Donoso, a los que con insistencia me invitaran los afectados.

Escribí algo sobre Nicanor Parra reprochándole la atmósfera de circo que sus admiradores habían creado en torno a su figura. Ahora pienso que cada cual tiene el derecho a celebrar su nuevo paso hacia la muerte como se le ocurra.

Respecto de José Donoso dije poco o nada. Hoy advierto, consternado, que el escritor ni me quiere ni me admira. Recientemente declaró en Las Ultimas Noticias lo que transcribo: "Pero si él no tiene ni voz ni voto en esto. Creo que está amargado el pobre, está deshecho de frustraciones". El "pobre" - continúa Lafourcade-, soy yo. Al paso le dedicó un piropo a Jorge Edwards, su gran amigo y 
reciente Premio Nacional de Literatura. Así le dijo: “Es un hombre de mucha inteligencia, pero quizá no tanta imaginación”. Es como decirle a un futbolista que tiene mucha inteligencia pero le fallan las piernas.

No sé de dónde sacó que yo vivía envuelto en tantas frustraciones y amarguras. No rendirle acato puede interpretarse de muchas maneras. Es una "personalidad" como dicen ahora. Pero confieso aquí, por mis muchas limitaciones, no haber podido deslumbrarme ante su obra. Acúsome, padre, de no haber terminado ninguna de sus grandes novelas. Y con las chicas, llegué al final gateando. (Lafourcade D32)

Al año siguiente, Donoso y Parra vuelven a coincidir, esta vez como invitados estelares en la Feria del Libro de Buenos Aires. Techy Edwards, agregada cultural de la Embajada de Chile en la capital argentina, recordaría luego en su libro José Donoso, voces de la memoria (1997) la recepción en la Embajada en honor a ambos:

El poeta, diez años mayor que el novelista, trepaba las escaleras sin dificultad, caminaba erguido, flirteaba con las señoras. En cuanto a Pepe, era evidente para cuantos lo veían que le costaba trabajo valerse solo. No se quejaba; pero hacía esfuerzos para estar alerta y seguir las conversaciones a pesar de la sordera de la que hacía gala en el último tiempo, manipulando su audífono muy obviamente. (Edwards 294)

Es probable que esa recepción en la Embajada haya sido la última vez que se vieron. Donoso estaba envejecido, aunque sus amigos no lo consideraran un signo preocupante. Se habían acostumbrado a bromear con las reacciones hipocondríacas de Pepe sin reparar que esta vez la cosa iba en serio. Era impensable que estuviera al borde la muerte. Pero falleció solo 18 meses después. También era inconcebible que Nicanor Parra viviera hasta los 103 años y así fue. Murió en 2018, cuando ya nos había convencido a todos que era inmortal.

Curiosamente, quizás no, tanto el poeta como el novelista eligieron ser enterrados a orillas del Océano Pacífico.

Nicanor Parra (1914-2018) yace en el jardín de su casa en la playa de Las Cruces en el litoral central. En ese mismo litoral, pero ciento cincuenta kilómetros al norte, en el Cementerio de Zapallar, está sepulta- 
do José Donoso (1924-1996). No se (des)carta que hayan reanudado su antiguo hábito de intercambiar correspondencia...

\section{Referencias bibliográficas}

Bocaz, María Laura. "La integración de José Donoso a la plataforma del Boom: intercambio epistolar inédito de José Donoso con Emir Rodríguez Monegal y Carlos Fuentes en la década del 60". Revista Iberoamericana, vol. 79, no. 244-245, julio-diciembre 2013, pp. 1049-1068.

División de Cultura del Ministerio de Educación de Chile. Eds. Donoso, 70 años. Santiago de Chile, Mineduc, 1997. Impreso.

Donoso, José y William Henkin. The TriQuarterly Anthology of Contemporary Latin American Literature. Eds. José Donoso y William Henkin. Northwestern, Northwestern University, 1969.

Donoso, José. Carta de su madre a José Donoso. 15 de febrero 1945. TS. José Donoso papers. Department of Special Collections, University of Iowa.

Donoso, José. Carta a Hans Erhman. 2 de junio 1970. José Donoso Papers. Department of Rare Books and Special Collections, Princeton University Library.

Donoso, José. Cuaderno 45, 18 de febrero 1974, p. 116-135. José Donoso papers. Department of Rare Books and Special Collections, Princeton University Library.

Donoso, José. Cuaderno 56, 2 de abril 1984, p. 139-140.

Donoso, José. Conjeturas de la memoria de mi tribu. Santiago de Chile, Editorial Alfaguara, 1997. Impreso.

Donoso, José. Historia personal del boom. Santiago de Chile, Debolsillo, 2018. Impreso.

Donoso, José. 1924-1996. "Quiero escribir una novela prescindible" [artículo] Gonzalo Contreras. Reseña. Archivo de Referencias Críticas. Recuperado de Biblioteca Nacional Digital de Chile http://www.bibliotecanacionaldigital.gob.cl/bnd/628/w3article-178824.html

Donoso, José. Carta a Hans Ehrmann. 2 junio 1970. José Donoso Papers. Department of Rare Books and Special Collections, Princeton University Library.

Donoso, José. “Parra reniega del código, la mesa y el reloj”. Revista Ercilla, 27 de julio, 1960, pp. 28-29. 
Donoso, Pilar. Correr el tupido velo. Santiago de Chile, Editorial Alfaguara, 2013. Impreso.

Edwards, Esther. José Donoso, voces de la memoria. Santiago de Chile, Editorial Sudamericana, 1997. Impreso.

El Mercurio. "Inauguran Plaza Portátil en honor a 'Nicanor Parra". El Mercurio [Santiago de Chile]. 23 de agosto 1994: 6. Impreso.

El Mercurio. "Parra: Hubiera preferido otra cosa”. El Mercurio [Santiago de Chile]. 31 de agosto 1994: C18. Impreso.

Erhman, Hans. Carta a José Donoso. 14 de julio 1970. José Donoso Papers. Department of Rare Books and Special Collections, Princeton University Library.

Guillén, Claudio. “Correspondencia epistolar y literatura. Ciclo de conferencias". Cursos Universitarios Fundación Juan March. Boletín informativo, no. 211, 1991, pp. 35-39.

Gumucio, Rafael. Parra, rey y mendigo. Santiago de Chile, Ediciones UDP, 2017. Impreso.

Lafourcade, Enrique. "Siguen los anti-homenajes a don José Donoso Yáñez". El Mercurio [Santiago de Chile]. 4 de septiembre 1994: D 32. Impreso.

Lafourcade, Enrique. "Este gato se está poniendo viejo". El Mercurio [Santiago de Chile]. 9 de septiembre 1994: D32. Impreso.

Parra, Nicanor. Carta a José Donoso. 28 de marzo de 1963. TS. José Donoso Papers. Department of Special Collections, University of Iowa.

Parra, Nicanor. Carta a José Donoso. 6 de enero de 1965. TS. José Donoso Papers. Department of Special Collections, University of Iowa.

Parra, Nicanor. Carta a José Donoso. 17 de marzo 1966. José Donoso Papers. Department of Rare Books and Special Collections, Princeton University Library.

Parra, Nicanor. Carta a José Donoso. 28 de abril 1966. José Donoso Papers. Department of Rare Books and Special Collections, Princeton University Library.

Parra, Nicanor. Carta a José Donoso. Mayo de 1970. José Donoso Papers. Department of Rare Books and Special Collections, Princeton University Library. 